\title{
Open Source Timber Systems as a Democratic Tool for Construction
}

\author{
Ulrich Dangel ${ }^{1 *}$ \\ ${ }^{1}$ Associate Professor, School of Architecture, The University of Texas at Austin \\ "Corresponding author's e-mail: dangel@utexas.edu
}

\begin{abstract}
Architecture, as it exists today, is deeply rooted in perceptions that were established during the Renaissance, which credited the architect as the sole author of creative thinking processes and the resultant design ideas. Since then, the architectural profession has desired to develop new and innovative ways of building, often without being bound by traditions, the environment, or any other constraints and limitations. This approach has frequently failed to address the needs and concerns of many. As a result, architects have not been successful in imparting significant social change that is valuable to large portions of the population. In contrast, however, many other industries have adopted shared design and production practices for the benefit of the masses, warranting further exploration into how architectural practice might evolve its current modes of operation.
\end{abstract}

Wood as a building material has many beneficial characteristics-specifically its widespread availability, versatility, and ease of workability-which make it particularly suitable for investigating shared authorship and collective production methodologies. As an alternative to steel and concrete for mid-rise and high-rise buildings, mass timber construction, in particular, has experienced significant advancements in recent years, resulting in the development of entirely new building processes that rely on innovative engineered wood products, digital manufacturing, and prefabrication techniques. However, this has frequently led to expensive oneoff proprietary solutions that are limited in their application. To foster innovation and disseminate knowledge, an open source culture of designing and sharing is necessary. To this end, this paper will present approaches for open source mass timber construction systems that can be applied to a wide range of scenarios and settings, with the aim of ultimately increasing the acceptance and market share of wood construction for the benefit of society at large.

\section{KEYWORDS}

Shared Authorship; Open Source Architecture; Timber Building Systems; Prefabrication

\section{AUTHORSHIP IN ARCHITECTURE}

The artistic ownership of a single author has been praised in the discipline of architecture as far back as Giorgio Vasari. The notion of an individual as the sole originator of iconic design ideas has continued today, fostering the image of the Starchitect. Thus, a small group of elite architects has emerged, which is responsible for designing a majority of high-profile contemporary buildings, from airport terminals to headquarters of global corporations, to museums. However, in their noble quest to change society, architects have increasingly ignored the needs and desires 
of a considerable portion of the world's population. They focus on buildings as iconic, singularly authored objects while often failing to respond to social concerns. Formal explorations and expressions frequently take precedence over human scale and functional needs. As a result, it is estimated that architects are involved in no more than two percent of global construction efforts today. Architecture has been unsuccessful at becoming a democratic tool that imparts significant change beneficial to large portions of society.

The origins of architecture, however, are intrinsically tied to the nameless contributions of many. Vernacular architecture was developed collectively in an anonymous fashion, carefully responding to the local climate, environment, and cultural values. Designs were modified, adapted, and optimized in response to the experiences and tried and tested methods of others, while slowly contributing to a large body of knowledge over time. Form and function were seamlessly combined into anonymous buildings, which were instrumental in shaping most of the world's great cities.

\section{OPEN SOURCE ARCHITECTURE}

To recognize the premise and potential of shared authorship architecture, one needs to understand the origins of open source models and their development throughout history. Open source as a term originated in the context of software development to designate computer software that had its source code made publicly available with a copyright license providing the rights to study, modify, and distribute the software to anyone and for any purpose. Today, the term open source describes a broader approach for projects, products, or initiatives that "embrace and celebrate principles of open exchange, collaborative participation, rapid prototyping, transparency, meritocracy, and community-oriented development." While contemporary architecture still operates under the sole authorship model established during the Renaissance, many other industries have embraced the shared design and production practices of the information age for the benefit of the masses, which includes joint efforts such as Linux, Wikipedia, and Creative Commons Licensing. Considering the multitude of challenges facing society - climate change, an exploding world population, and increasing economic inequality-it is timely to question current modes of operation within architectural practice.

Several open source initiatives have emerged over time in the discipline of architecture. The Open Architecture Network, for example, was developed by the US-based charitable organization Architecture for Humanity and launched in 2007. Discontinued in 2015, it was an online, open source community dedicated to improving global living conditions through innovative and sustainable design. More recently, WikiHouse was initiated as an open source project to reinvent the way houses are made. It is being developed by architects, designers, engineers, inventors, manufacturers, and builders who are all collaborating to create the best, most straightforward and sustainable high-performance building technologies that anyone can use and improve.

Some industry organizations offer free databases related explicitly to timber construction. Holzforschung Austria, the Austrian Forest Products Research Society, maintains an extensive technical online library of structural and non-structural wood products, components, assemblies, and details at dataholz.eu. Lignum Holzwirtschaft Schweiz, the umbrella organization of the 
Swiss forestry and timber industry, provides a building component catalog focused on the acoustic properties of assemblies at lignumdata.ch. Furthermore, MetsäWood, a Finnish wood products manufacturer, has recently launched its Open Source Wood initiative. As an open ideas platform, it focuses on sharing innovative knowledge to foster modular wood construction. Architects and engineers can submit modular building elements using Creative Commons license type CC-BY 4.0, which allows content creators to grant someone else permission to use their work. Sharing information and disseminating knowledge through the development and promotion of open source design strategies is a logical next step for democratizing architecture. This approach has the potential to broaden the reach of the architectural profession while simultaneously making its impact on humankind more meaningful. Most importantly, however, it could provide large swaths of the world's population easy access to thoughtfully designed and carefully constructed buildings, satisfying their need for adequate places for living and working. Open source design methodologies also remove control that relatively few might be able to exert over many by inviting contributions from all. Rather than a small group of creators providing deterministic design solutions for large portions of society, design becomes a fluid and participatory process.

\section{SYSTEMS IN ARCHITECTURE}

Due to the many authors involved, open source design can only be successful if a common language is employed by all participants to coordinate processes and methods. Thinking in systems has long been utilized in architecture as a holistic approach to establish how individual components interrelate with each other in the context of larger and more complex constructs. Early vernacular construction techniques unitized buildings through the use of modular stones, brick, and timber members. However, it was the ability to manufacture identical building elements in large quantities and to exact standards during the industrialization that laid the foundation for the development of building systems. Prefabricated iron-and later steelcomponents were essential in enabling the construction of large and systematic infrastructure projects such as bridges and train stations. In the late $19^{\text {th }}$ and early $20^{\text {th }}$ century, new industrialized production methods were hailed as a solution for many economic and social issues at the time. Most importantly, it was hoped that relying on these technological advancements would resolve the housing shortage that was caused by the migration of working-class laborers to the urban industrial centers in search of employment.

\section{Closed Systems}

The continued development of prefabricated construction systems was interrupted by the economic crisis of the 1920s as well as the outbreak of World War II, which shifted the focus of industrial production to armaments manufacturing. The need for rebuilding in the post-war years ushered in a new era for industrial fabrication. New prefabricated building systems were conceived, ranging from solutions for affordable housing to large span structures for commercial and industrial applications. System building became synonymous with progress in the 1950s and 1960s. The rationalization and standardization of design and construction processes resulted in the repetitive use of identical elements, which led to a new aesthetic and redefined the concept of beauty in architecture. Many architects and designers employed construction systems as a vehicle to propose bold visions for the future of buildings and even entire cities. In the end, this blind reliance on technology to solve the social and economic issues of the time was rejected. 
Substandard quality of construction, poor urban planning strategies, and the relentless uniform appearance of buildings- among many other concerns-meant that the general public increasingly grew disillusioned with building systems. This was in part due to the fact that the self-contained, deterministic nature of the concepts conceived in the 1960s did not provide enough flexibility to respond to individual needs. Within these so-called closed building systems, nothing could be easily removed or added, significantly reducing the ability to respond to users' changing demands over time.

\section{Open Systems}

While serial production with identical components seems to have gained widespread acceptance in many other industries such as automobile and aircraft manufacturing, a comparable approach in architecture has not been well received by society. Additionally, the more common development of closed building systems has imposed even greater limitations since they use proprietary components or subsystems that are designed and developed exclusively for use within the system, eliminating the ability to integrate third-party building elements or products. In contrast, an open building system concept consists of exchangeable components or subsystems that often come from different manufacturers, thus increasing choice and flexibility for both the designer and user (Fig. 1). Open systems can provide overarching order while still allowing freedom for individual customization. They also facilitate alterations that might occur due to a change of use or shifting user needs. This approach has the potential to make a structure significantly more resilient than its less adaptable neighbors since repurposing increases a building's acceptance by its occupants, thereby extending its lifespan over time. Through their flexibility, open systems are also able to respond more readily to localized conditions, whether they are cultural, social, environmental, or economic in nature.
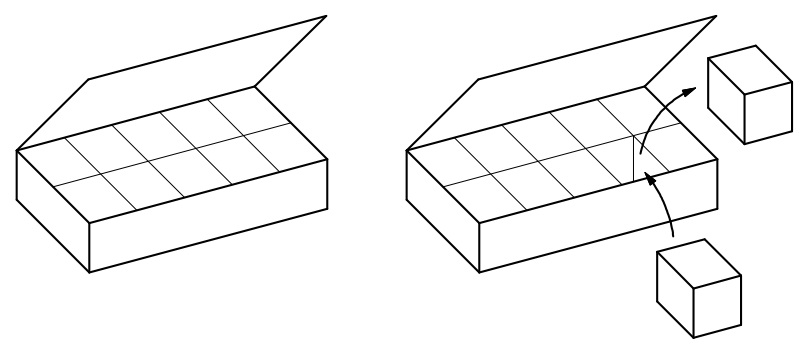

Figure 1. Closed system: proprietary components or subsystems (left) vs. open system: exchangeable components or subsystems (right)

\section{OPEN SOURCE, OPEN SYSTEMS IN TIMBER}

\section{Light Frame Construction}

Within the context of building with wood, the nowadays ubiquitous platform framing method, which emerged as an improvement to balloon framing in the early $20^{\text {th }}$ century, can be considered the ultimate open source, open building system. It is a construction system that is based on the use of standardized 2x structural members that are assembled with standard, massproduced nails. Rules of thumb are employed for member spacings of 16 " or 24" on center, and standard connection details are common knowledge or readily accessible through freely available 
reference literature. The use of minimal structural material allows the enclosure of large areas at minimal cost while allowing a wide variety of architectural styles. Originally conceived as a technique that facilitated assembly by unskilled or untrained labor, it is possible to create an entire building without the involvement of a designer, architect, or engineer by merely following the established rules. The method's ease of adjustability in the field is one of its major advantages but also leads to its most significant disadvantages, in particular, its inefficiency of on-site assembly and the potential to generate substantial amounts of construction site waste compared to prefabrication. Due to its flexibility, low cost, and ease of assembly, platform framing continues to dominate residential and small-scale commercial construction in North America.

\section{Panel Construction}

Inspired by North American platform framing, panel construction emerged in Europe as a technique that offered significant advancements in timber construction, most importantly higher levels of prefabrication and improved quality of craftsmanship. While the structural logic of panel construction is the same as for platform framing-a framework of load-bearing members that is laterally braced through sheathing-entire wall, floor, and roof panels are prefabricated and then transported to the site for final assembly. As an open source, open system, panel construction takes advantage of wood's many beneficial characteristics-in particular, its lightness and ease of workability-by shifting design and production processes into the shop. This allows the designer and fabricator to exert more control over the final product, which ensures consistency and precision while simultaneously facilitating quality assurance. Shop fabrication also provides more efficient use of material and significantly decreases the amount of on-site construction waste, which would otherwise have to be disposed of as landfill. One major advantage of panel construction is that fact that it does not require highly specialized equipment, which means that any qualified carpentry business can easily perform the necessary tasks for production.

\section{Solid Timber Construction}

Recent technological innovations have led to the development of load-bearing, large-format components that far exceed the structural limitations of more common timber building products. With its ability to resist both gravity loads and lateral forces, cross-laminated timber (CLT) in particular has revolutionized the construction sector. Increased load-bearing capacities have opened up possibilities to construct taller multi-story structures, allowing timber to compete with more energy-intensive building materials such as steel and concrete. These new solid timber-or mass timber-building systems not only have the potential to provide an affordable, low-carbon solution to the housing crisis in urban areas around the world. They also offer improved quality of construction, thermal mass for increased comfort, enhanced fire performance compared to frame or panel construction, as well as exposed interior wood surfaces that have shown to improve physical and mental health for occupants.

Mainly conceived in Western Europe and North America, mass timber systems have led to the development of entire new building processes for timber construction, but at the same time rely heavily on high-level engineering expertise and specialized production technologies. The wide range of production equipment and processes has also resulted in each manufacturer developing their own proprietary cross-laminated timber elements, which is reflected in the large variety of 
layups and dimensions available on the market today. This lack of standardization may force a design team to settle on a specific product from a particular supplier early on for design and planning purposes, effectively eliminating any competition at the very onset of a project. Due to a concentration of know-how as well as significant start-up costs, the location of fabrication facilities is currently limited to industrialized nations, frequently requiring the distribution and shipment of products over long distances and even overseas. Since they have had the opportunity to streamline production processes over time, larger well-established manufacturers are often able to offer more competitive pricing than start-up suppliers that might be more local.

\section{TOWARD AN OPEN SOURCE, OPEN HYBRID TIMBER SYSTEM}

Classifying timber construction into discrete techniques such as light frame, panel, or solid timber construction no longer seems reasonable since combining building components that employ different systems has mostly become standard practice. Each building element is selected for a particular application based on its unique properties, which results in optimized hybrid structures. This approach offers designers a large amount of freedom during the planning process to arrive at highly tailored solutions.

To this end, this paper proposes the implementation of a low-tech open source, open timber system that can be applied to a wide range of building scales, socio-economic scenarios, and markets. The primary objective is to establish strategies that enable the provision of sufficient sustainable and affordable housing in urban areas, particularly in emerging economies that struggle to meet the growing demands while simultaneously satisfying economic, ecological, and social concerns. These countries might possess vast forest stocks, but likely neither have a wellestablished or sophisticated timber products industry nor have traditionally focused on building with wood. The promotion of timber construction has the potential to offer alternatives to more carbon-intensive construction methods by introducing more sustainable building practices.

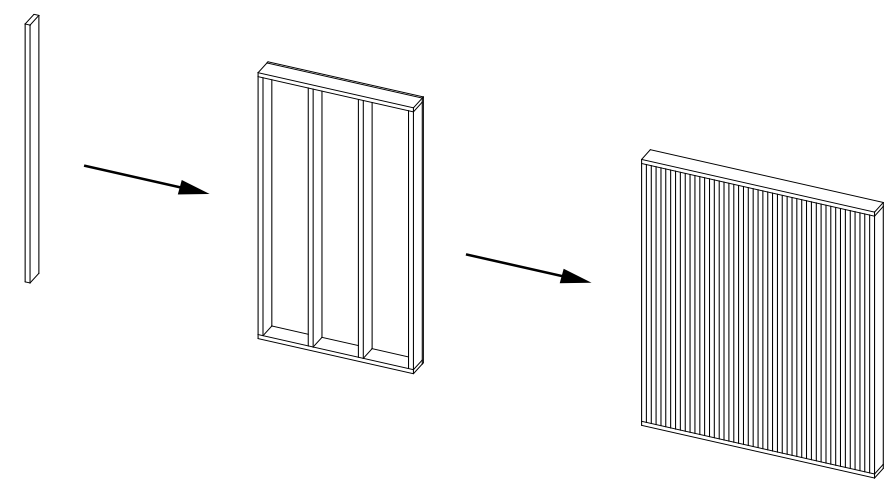

Figure 2. Gradient from platform framing, to panel construction, to mass timber construction. Conceived as a hybrid system, the proposed solution is intended to operate across a gradient of construction methods. By employing this strategy, it takes advantage of the flexibility and cost efficiency of platform framing, the prefabrication benefits and quality control inherent to panel construction, and the improved structural performance and thermal properties of mass timber (Fig. 2). Reliance on (locally) readily available commodity products allows the system to respond to localized conditions-whether they are cultural, environmental, or economic. Rather 
than promoting a universal formal language, it emphasizes architecture as a product of place, material, and function.

Where a particular design solution falls within the spectrum depends heavily on several factors: Building height, required load-carrying capacities, local building and fire codes, availability of raw materials, and skill set of the local workforce. Rather than relying on the fabrication of laminated components such as cross-laminated timber and glulam that might require specialized equipment, this method proposes an additive approach to handle increasing gravity loads for floors and walls that is similarly found in platform framing: Heavier loads are therefore accommodated by combining several smaller structural members together into larger cross sections. Joining individual boards together can be accomplished with mechanical fasteners such as nails (nail-laminated timber or NLT) or hardwood dowels (dowel-laminated timber or DLT). The appropriate bonding technique can be selected based on local construction practices and availability of equipment. Nailing is undoubtedly considered the simplest method, but the presence of non-wood fasteners in the final product may pose limitations on workability and recyclability. While the use of hardwood dowels requires an increased level of craftsmanship, an all-wood product greatly facilitates processing as well as end-of-life material recovery and repurposing. This configuration of members allows the wood to be primarily loaded parallel to the grain, which offers exceptional strength to resist vertical gravity loads. However, the addition of lateral load-resisting components such as structural sheathing or diagonal bracing is required to transfer lateral loads successfully. By allowing the structural system to readily respond to both specific load patterns and local conditions, the transition from lightweight wood framing to solid timber construction becomes seamless (Fig. 3).

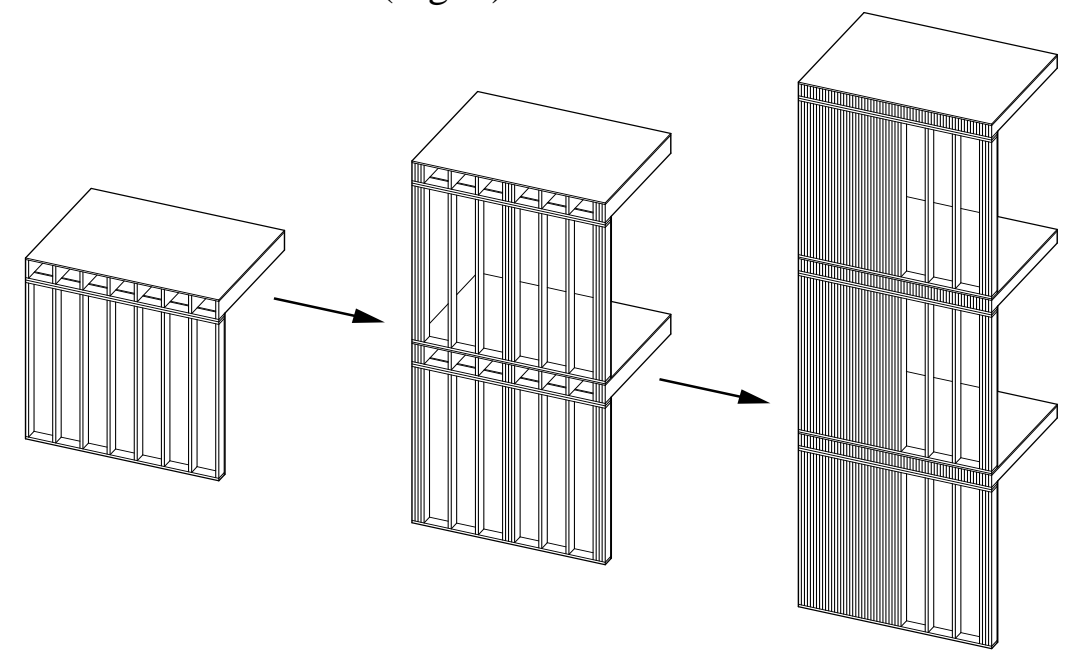

Figure 3. Seamless transition between construction methods.

Crucial for the successful dissemination of the proposed open timber strategy is an online portal that allows free access to technical information as well as the sharing of knowledge. Using Creative Commons licensing, any user can propose and distribute new building components within a defined set of rules, but they can also freely copy and make derivatives of the work of others. Rather than a single entity possessing ownership and control over proprietary and static information, this participatory, open source process allows the development of tailored, localized design solutions that can respond to a variety of economic, environmental, cultural, and social scenarios with the intention of satisfying the housing needs for many. 


\section{CONCLUSION}

As an interim report, this paper lays the foundation for an open source, open timber system while proposing an overall conceptual framework for its implementation. Valuable feedback from the general public, architects, engineers, developers, and anyone involved in the built environment is currently being solicited and will be incorporated into the research as the conceptual development and technical resolution continues.

\section{REFERENCES}

Educational Facilities Laboratories (1967) SCSD: The Project and the Schools. Educational Facilities Laboratories: New York, NY, USA.

Dangel U. (2017) Turning Point in Timber Construction: A New Economy. Birkhäuser, Basel, Switzerland.

Holzforschung Austria. "Dataholz.eu" Dataholz.eu <https://www.dataholz.eu/en.htm> (Jan. 9, 2019).

Kaufmann H., Krötsch S., and Winter S. (2018) Manual of Multi-Storey Timber Construction. Detail, Munich, Germany.

Landsberg, H., and Pinkau, S. (1999) Holzsysteme für den Hochbau: Grundlagen, Systeme, Beispiele. Verlag W. Kohlhammer, Stuttgart, Germany.

Lignum Holzwirtschaft Schweiz. "Bauteilkatalog Schallschutz" Lignumdata.ch $<$ https://lignumdata.ch> (Jan. 9, 2019).

MetsäWood. "Open Source Wood Initiative" Opensourcewood.com $<$ https://www.opensourcewood.com> (Jan. 9, 2019).

OpenArchitectureNetwork.org. "About the Open Architecture Network" Archived version of OpenArchitectureNetwork.org <https://web.archive.org/web/20150315015711/http://openarchitecturenetwork.org/about> (Jan. 9, 2019).

Opensource.com. "What is open source?" Opensource.com <https://opensource.com/resources/what-open-source> (Jan. 9, 2019).

Ratti C., and Claudel M. (2015) Open Source Architecture. Thames \& Hudson London, UK.

Staib, G., Dörrhöfer A., and Rosenthal M. (2008) Components and Systems: Modular Construction. Birkhäuser, Basel, Switzerland.

St. Laurent, A. M. (2008) Understanding Open Source and Free Software Licensing. O'Reilly Media, Sebastopol, CA, USA.

Vasari, G. (1550) Le Vite de' più eccellenti pittori, scultori, e architettori. Torrentino, Florence, Italy.

WikiHouse. “About” Wikihouse.cc <https://wikihouse.cc/about> (Jan. 9, 2019). 